\title{
Stand-alone backup power system for electrical appliances with solar PV and grid options
}

\author{
A. H. Sabry ${ }^{1}$, Wan Zuha Wan Hasan ${ }^{2}$, Farah Hani Nordin ${ }^{3}$, Mohd Zainal Abidin Ab-Kadir \\ $1,3,4$ nstitute of Power Engineering (IPE), Universiti Tenaga Nasional (UNITEN), Malaysia \\ ${ }^{2,4}$ Electrical and Electronics Department Engineering, Universiti Putra Malaysia (UPM), Malaysia \\ ${ }^{2}$ Institute of Advanced Technology (ITMA), Universiti Putra Malaysia (UPM), Malaysia
}

\section{Article Info}

Article history:

Received May 10, 2019

Revised Jul 11, 2019

Accepted Jul 25, 2019

\section{Keywords:}

Backup power supply

Control methods

Energy storage

Topologies

\begin{abstract}
For a portable backup power system, there is an essential need to contribute to increasing the energy conversion efficiency between the source and the electrical household appliances to overcome the recent issues of global warming. This paper proposes a Backup power system (BPS) compatible with the capability to match with two primary power sources; GridConnected power as an AC and solar-PV as a DC power source. This system composes of a rechargeable battery bank of about $300 \mathrm{~V}$, while the voltage matching concept keeps maintaining the battery fully charged as long as the source power is available. MATLAB-based simulation has performed to prove the concept of the adopted voltage-matching. A relay switch circuit controlled by the main power source is used to change-over the load/appliances between direct link through bypassing the main power and the storage battery power when both options of main power are unavailable. The result shows the excellent utilization of the traditional BPS losses, the proposed topology can achieve about $99 \%$ power efficiency as compared with the traditional one.
\end{abstract}

Copyright @ 2020 Institute of Advanced Engineering and Science. All rights reserved.

Corresponding Author:

Ahmad H. Sabry,

Institute of Power Engineering (IPE),

Universiti Tenaga Nasional,(UNITEN), Selangor, 43000, Malaysia

Email: ahs4771384@gmail.com; wanzuha@upm.edu.my

\section{INTRODUCTION}

To overcome recent issues of greenhouse gas emission and global warming, usage of renewable power resources is enormously increasing, in this context, there is a need exists for a reliable, quiet and efficient source of backup power for supplying power to appliances. Grid-connected or solar PV-power backup power system (BPS) provides a clean, conditioned system to utilize the energy for a longer period of time. Commercially all the backup power systems need to satisfy the load requirements to maintain the required performance for the appliance. Although sometimes the BPS ignorantly dismiss as merely a (battery in a box), they are in fact complex devices that carry out various functions, at least of which is securing clean energy for electrical equipment. as long as the complexity of these backup devices increase, their maintenance requires more efforts and expense to minimize the risk of failure.

Currently, BPS must provide an output with regulated sinusoidal at low total harmonic distortion (THD), regardless the variations in the input voltage and rapid changes in the connected load to the system [1]. In addition, the low transient response for the online mode to the battery-powered mode and viceversa, high reliability, unity power factor, high efficiency, low weight, small size, and low cost ..etc. that are further necessary considerations in the BPS.

Generally, the BPS can be divided into static systems and rotary systems. The static systems use converter and inverter with power electronics to store, process, and deliver the power at grid-failure, in contrast, Rotary systems use generator and motor to perform the same functions. Another type, 
that combines both static and rotary systems, called hybrid BPSs [2, 3]. Most BPSs available in the markets according to their power ratings, starting from only 300VA to provide backup power to one computer, to the bigger units that may provide backup power to a complete building with a number of a megawatt. The BPSs can be classified depending on their topological design, the offline BPS, Line-interactive BPS, and online BPSs [4-8].

As mentioned above, all the invented and the proposed BPS systems included the DC/AC inverter as the main element to drive the appliances with the AC power, which is not the same in this work. This work relates to a backup power system to provide power to household appliances such as; all major residential and small commercial end-users, including electronic lighting (fluorescent or LED), cooling, space and water heating, clothes washing, and motors, water pumps or compressors (in particular in variable-speed operation where appropriate). It is worth to mention that this work is extended from our work in [9]. Commercially all the backup power systems need to satisfy the load requirements to maintain the required performance for the appliances.

To contribute in reducing the environmental pollution and the noisy apparatuses usage that are still used to maintain electric power in public markets or hawkers areas (e.g. PASAR-MALAM in Malaysia), where the utility grid power is not available, the rechargeable backup power system with the appropriate size and energy storied is a suitable solution. This size of apparatus can be generalized to cover the needs of electricity, as an emergency backup power, anywhere suffer from power outages problems or during the blackout due to storms, accidents, and countless other circumstances. Therefore, the work is the alternative green power supply for internal combustion generators and can be scalable according to load demands.

The proposed solar PV-powered backup power system with grid-connected option can provide a clean conditioned system to utilize energy for a longer period of time. The proposed topology relates to a DC-distribution based backup power system by only passive components, with high efficiency as compared to the previously disclosed. It provides power to household appliances such as; all major residential and small commercial end-users, including electronic lighting (fluorescent or LED), cooling, space and water heating, clothes washing, and motors, water pumps or compressors (in particular in variable-speed operation where appropriate).

\section{RESEARCH METHOD}

Unlike the techniques outlined in the literature, the proposed technique through the concept (sourceload voltage matching) keeps maintaining the flow of current under the ideal equilibrium constraints, that can be defined as:

$$
V_{m p} \cong V_{\text {bat.max }} \cong V_{L}
$$

Where $V_{m p}, V_{\text {bat.max }}, V_{L}$ denote the voltages of; PV at maximum power, system battery at full charge state, and the load, respectively. The presented work reduces the complexity of a conventional controller via avoiding the power losses that occur wherever a switching component exists.

The concept of design is basically based on the variation range of the site geographic parameters, the solar irradiance, and temperature over $70 \%$ of effective daytime. It starts from the value of the appropriate level of load voltage $\left(V_{L}\right)$ to be ideally assigned as the full charge voltage of the system battery bank $\left(V_{\text {bat.max }}\right)$. A check is essential for the voltage to be approximately subjected to the formula $\left(V_{\text {bat.max }} \cong\right.$ $V_{L}=13.5 * k$ ) where $k$ is an integer $k \in\{\mathbb{Z}\}$, and value 13.5 represents the voltage level at which the lead acid battery reaches its full charge. Next, the PV parameter $\left(V_{m p}\right)$, which denotes the PV voltage at maximum power, is supposed to subject the formula $\left(V_{m p} \cong V_{\text {bat.max }}+V_{d}\right)$, where $V_{d}$ is the forward voltage drop of the parallel diodes, the tuning value depends on the type and number of the parallel diodes, higher parallel diodes lower drop voltage. The maximum PV power $\left(P_{m}\right)$ and the amount of energy storage capacity is specified depending on the demand in $\mathrm{kWh}$. The remaining parameters such as; short circuit current $\left(I_{s c}\right)$ and the open circuit voltage $\left(V_{o c}\right)$ are extracted accordingly. is selected to be 23 to get the $\left(V_{\text {bat.max }} \cong V_{L} \cong 310.5\right.$ ), which is equivalent to the DC value of the utility grid to provide the connectivity with major priority due to its availability.

The proposed work presents a backup power system specifically designed to deliver substantially backup power at the main power failure for household appliances. The system composes of a seriesconnected rechargeable battery with about $300 \mathrm{~V}$ to be near the supply voltage, a battery charging circuit, which manages supplying power to the appliances while a main power outage, There is no DC-AC inverter, which is the property that recognizes this system as a more efficient system as compared to other related work in the prior art. Therefore, a DC power is supplied from the battery bank to the traditional household 
appliances. The system also has a relay-switch energized by the main input source for switching to the backup power of the battery during power failures. The system has the ability to be working as a stand- alone system. The system can be handled to place near the appliance similar to a laptop power supply unit. The system can be charged by the suitable solar PV or from the wall outlet to provide power to charge the battery and can maintain the power simultaneously.

Several features of DC-DC conversion circuits can be used for battery charging from PV source. In this work, the conventional boost converter is chosen due to it is a generally-used topology with high reliability as compared to other complex configurations $[10,11]$. This converter employed as a solar-battery charge controller [12], and PFC applications [13], the circuit can be represented as shown in Figure 1.

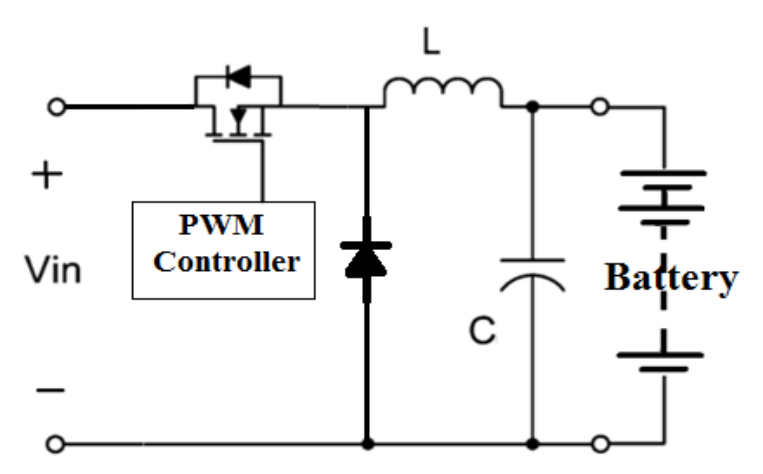

Figure 1. Conventional DC powered battery charger

The state-space average equations are utilized to model the converter as expressed in (1) [13].

$$
\begin{aligned}
& \dot{X}_{1}=\frac{1}{L} V_{\text {in }} u-\frac{1}{L} X_{2} \\
& \dot{X}_{2}=\frac{1}{C} X_{1}-\frac{1}{C R_{\text {bat }}} X_{2}
\end{aligned}
$$

Where $u$ is the duty cycle, and $\left[\begin{array}{ll}X_{1} & X_{2}\end{array}\right]=\left[\begin{array}{lll}i_{L} & V_{b a t}\end{array}\right]$, the main inductor current and the battery voltage, respectively. $\mathrm{R}$ is the battery bank resistance value.

When the power level rises, the diode losses and inductor volume considerably reduce the circuit efficiency and the heat dissipation becomes difficult in a limited area. The dependence on controlling the charging process will be on the battery/load voltage $V_{b a t} \cong V_{L}$ where the duty cycle $\mathrm{D}$ is proportional to that value. Thus;

$$
V_{b a t} \cong V_{L}=f\left(i_{L}\right)
$$

Where $i_{L}$ is the load od the PV system. The battery/output voltage of the circuit can be presented as a function of the PV/input voltage $V_{p v}$ and its duty cycle D:

$$
\frac{V_{b a t}}{V_{p v}}=\frac{1}{1-D}
$$

This equation describes controlling the battery voltage by varying the converter duty cycle D. Since our work here considers the above conventional boost converter, experimental power measurements have been conducted to evaluate the circuit efficiency with respect to a voltage level and to verify its operation. The components; diode (IDB06S60C), MOSFET (IPB60R099CP), an inductor (400H), Capacitor $(1000 \mathrm{~F})$ were used to implement the experiment. The DC input voltage is about $300 \mathrm{~V}$ which is equivalent to 22 units of a full charge 12V/65Ah lead-acid battery each. Efficiency versus output power at different battery voltages for a conventional boost converter is shown in Figure 2.

Figure 2 shows the efficiency of a DC-DC boost converter at battery voltages ranging from $72 \mathrm{~V}$ to $264 \mathrm{~V}$, which represents $6-22$ units of the $12 \mathrm{~V}$ battery. It is obvious from the curves, the circuit performs with lower efficiency at the lower level of battery voltage. This result enhances the proposed concept which considers the balancing between the source and the battery voltages, where the solar voltage at maximum power is designed to be approximately equal to the full charge value of the battery bank. 


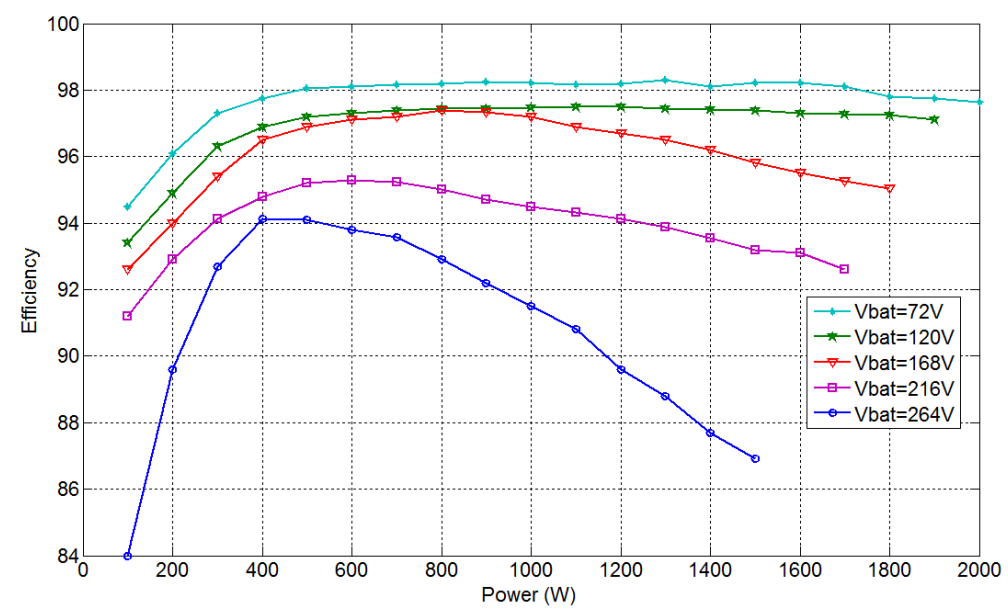

Figure 2. Efficiency versus output power at different battery voltages for a conventional boost converter

\subsection{Comparison between the Traditional and the Proposed System}

The main components of the current BPS can be listed as in Table 1, which also compare between the traditional and the proposed BPS in terms of the existence of these components.

Table 1. The Main Components of BPS and Their Existence in the System

\begin{tabular}{|c|c|c|c|}
\hline $\begin{array}{c}\text { Component } \\
\text { name }\end{array}$ & Function description & Traditional system & Proposed system \\
\hline Battery & $\begin{array}{l}\text { is the BPS energy storage element. Each battery package includes } \\
\text { at least one string of cells, and based on BPS configurations, } \\
\text { unlimited cell strings may be extended to prolong runtime and/or } \\
\text { redundancy. }\end{array}$ & $\begin{array}{l}\text { Generally }(1-4) \\
\text { package lead-acid. } \\
(123 \mathrm{Ah} * 12)- \\
(35 \mathrm{Ah} * 12 * 4) \\
=(1.48-1.665) \mathrm{kWh}\end{array}$ & $\begin{array}{l}\text { (80-90) Lithium-ion cells } \\
\text { each of }(5 \mathrm{Ah} * 3.7 \mathrm{~V}) \text { to } \\
(1.48-1.665) \mathrm{kWh}\end{array}$ \\
\hline Rectifier & $\begin{array}{l}\text { Is used to perform two essential functions: converting incoming } \\
\text { utility power from AC to DC and charging the batteries. }\end{array}$ & $\begin{array}{l}\text { Full bridge rectifier and } \\
\text { filter, usually a set of } \\
\text { passive components }\end{array}$ & $\begin{array}{l}\text { Same as in the traditional } \\
\text { system }\end{array}$ \\
\hline Inverter & $\begin{array}{l}\text { The inverter within a BPS accepts the DC from the DC bus } \\
\text { (Battery or battery bank), which is supplied by the rectifier and } \\
\text { the battery. During a power outage, the } \\
\text { rectifier will no longer provide current to the D/C bus, leaving } \\
\text { the battery to support the load. Its efficiency is }(40-95) \% \text { depends } \\
\text { upon the demand power and its brand. }\end{array}$ & $\begin{array}{l}\text { Exist as a main } \\
\text { component to supply } \\
\text { the appliances with } \\
\text { AC }\end{array}$ & $\begin{array}{l}\text { Not exist. } \\
\text { Therefore, saving } \\
\text { between }(60-5) \% \\
\text { according to the load } \\
\text { power. }\end{array}$ \\
\hline $\begin{array}{l}\text { Static } \\
\text { bypass }\end{array}$ & $\begin{array}{l}\text { it provides close the circuit automatically and allows the } \\
\text { incoming power to divert around the rectifier, batteries, and } \\
\text { inverter. Although the power supply is not conditioned, the static } \\
\text { bypass lets critical systems continue functioning even if the BPSs } \\
\text { components fail. }\end{array}$ & $\begin{array}{l}\text { Usually, it is the relay } \\
\text { switching circuit. }\end{array}$ & $\begin{array}{l}\text { Same as in the traditional } \\
\text { system }\end{array}$ \\
\hline
\end{tabular}

The main objective of this research is to build a BPS with more efficiency and flexibility to accept two types of input power; AC, from the utility grid, and DC, from the Solar PV array. This design adopts two concepts disclosed in the literature:

a) Its interconnection strategy is inspired by the concept of source-load Voltage Matching, which has described in our previous efforts in [14-16].

b) The prior art shows that the DC-distribution system has the best impact on the performance of the current household [17-22].

To clarify the hypothesis of the proposed work, Figure 3 illustrates the BPS comparison between the traditional, as in the literature, and the presented in this work. In this context, A BPS systems with hybrid power sources have been presented in [23-27] In these systems, super-capacitor and the battery are combined as such to make sure sufficiently energy available to provide backup power to load. When the utility grid power is a blackout, the rechargeable battery will be connected together with the super-capacitor to respond quickly to the external load. The diagram of the hybrid BPS system is demonstrated in Figure 4. 


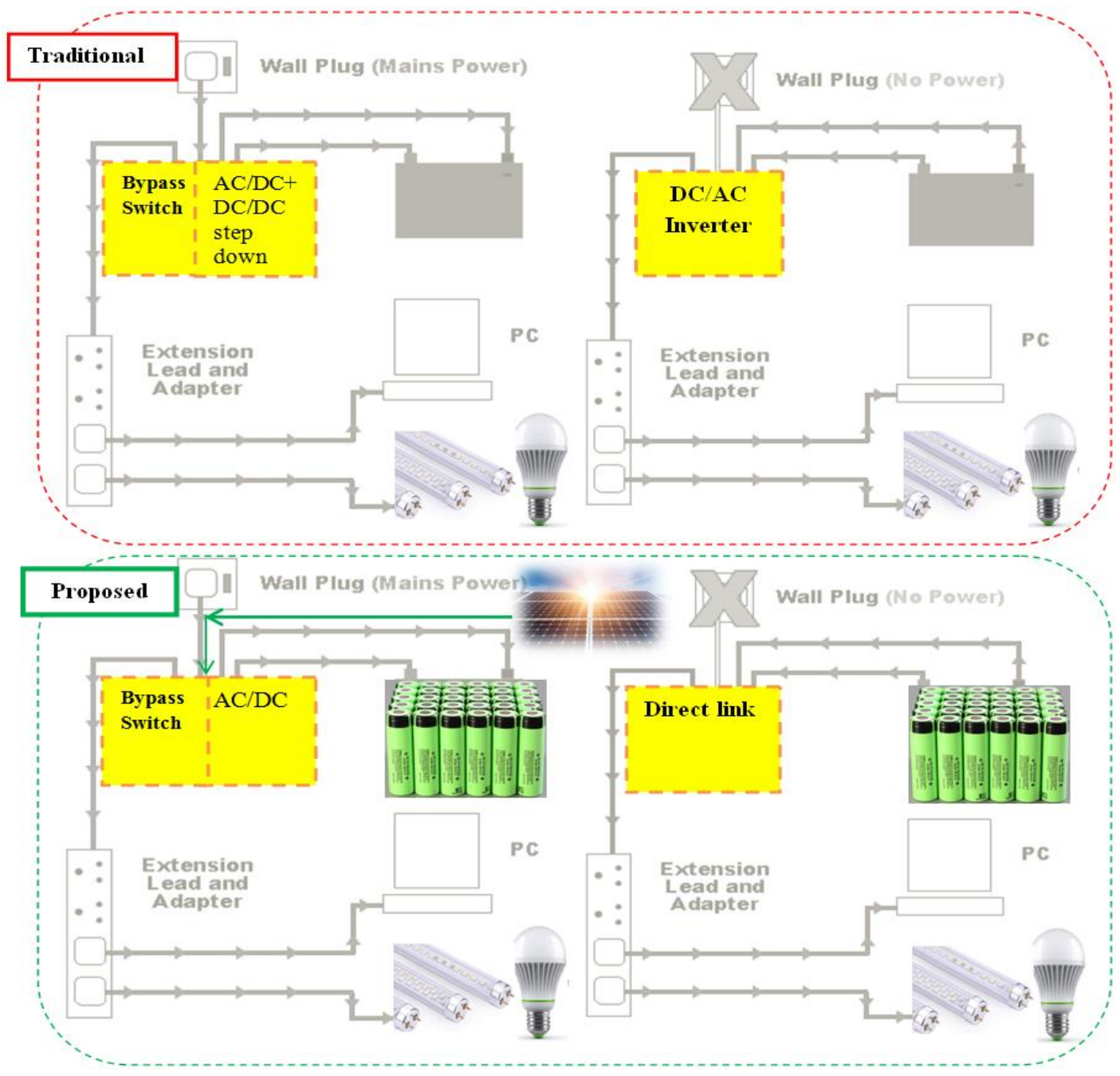

Figure 3. Illustrates the comparison between the traditional and the invented backup power system

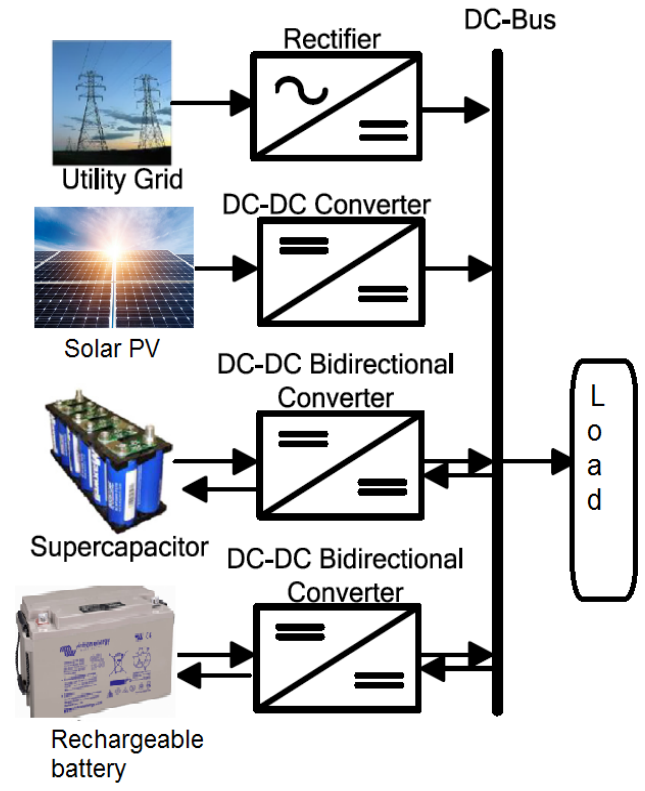

Figure 4. The diagram of the hybrid BPS system 


\subsection{Linear and Switching DC/DC Converter, and the Proposed Direct-Link Comparison 2.2.1 Linear DC/DC Converter}

The linear converter is a good choice for providing power with a very low amount to applications or devices. Although they are easy to employ, cheap and simple, the linear converters are in general inefficient. We can write the equation for dissipated power ( ) for this type of power converter as:

The linear converter uses the linear, non-switching technique to convert the power output of the power supply. The converter's resistance differs according to the power of load and results in a constant output voltage. Most linear converters require that the input voltage be higher than the wanted output level voltage. This difference in voltage is called the dropout. Low dropout converter is a DC linear converter that can control the output power even when the input voltage at a level close to the output. Therefore, the linear converters are simple and cheap solutions but are in general inefficient because the input-output voltage difference is frequently dissipated as heat. The representation of the linear DC/DC converter can be shown in Figure 5.

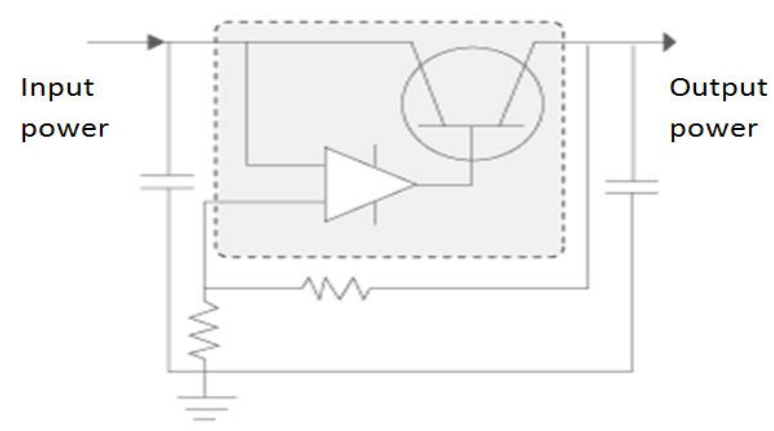

Figure 5a. Linear DC/DC converter

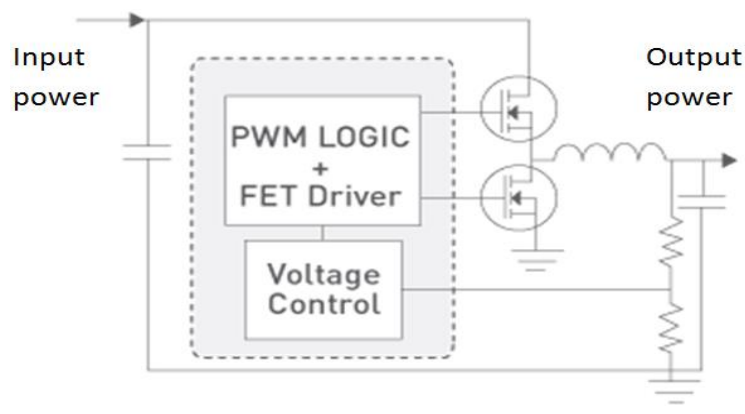

Figure 5b. Switching DC/DC converter

\subsubsection{Switching DC/DC Converter}

Switching converter is higher efficiency than the linear type and it is obtainable in a single chip, which is compact in size and reliable. This converter can be subdivided into isolated, and non-isolated. With this type of converter, several key requirements for the energy management nowadays solution which includes lower power consumptions under a variety of load environments, high reliability, less space, and large input voltage range. Those needs are driving the requirement for higher efficiency with a wider range of input voltage for converters in wide applications.

\subsection{Proposed Direct-Link Converter with the BPS}

The direct-link BPS consists of a battery charger, a static switch, and a backup rechargeable battery shown in Figure 6. A surge suppressor and filter are occasionally used at BPS output to avoid the noise of the input AC source and the disturbance before being delivered to load at the output. At normal operation mode, the charger charges the battery bank and simultaneously supplying power to the load the input AC source. There is no inverter in this topology therefore, no conversion losses were generated during this mode. At power failure or blackout, the static switch disconnects the load from the source leaving the connection with the battery bank. 


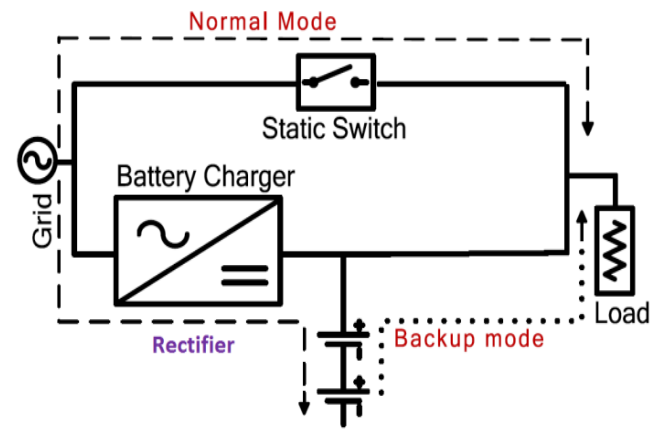

Figure 6. Block diagram of the proposed direct-link converter with the BPS

\section{RESULTS AND ANALYSIS}

A simulation with MATLAB has been designed to implement the three types of converters when handling the power from the source to the load in the BPSs. The basic designs, that have been described above in the methodology section of this report, were employed to perform the comparison among the three addressed converters. One ampere step-size division selected from 10 amperes as a maximum delivered current to the load. The efficiency, which is the power output to the power input multiplied by $100 \%$, of the converter, was calculated each time of 1 Amp load current. It is observed that the linear converter has a constant efficiency value over the current variations, while a sharp growing up to about $89 \%$ efficiency is achieved when the switching DC/DC converter is performed, but it still has losses especially at lower load current. These losses are due to the switching of the semiconductor devices such as the MOSFETs or IGBTs. The proposed direct link perform better than both other converters because it links the source with load directly, only a few losses were dissipated due to the passive diodes and the fuse resistors. All those information are shown graphically in Figure 7.

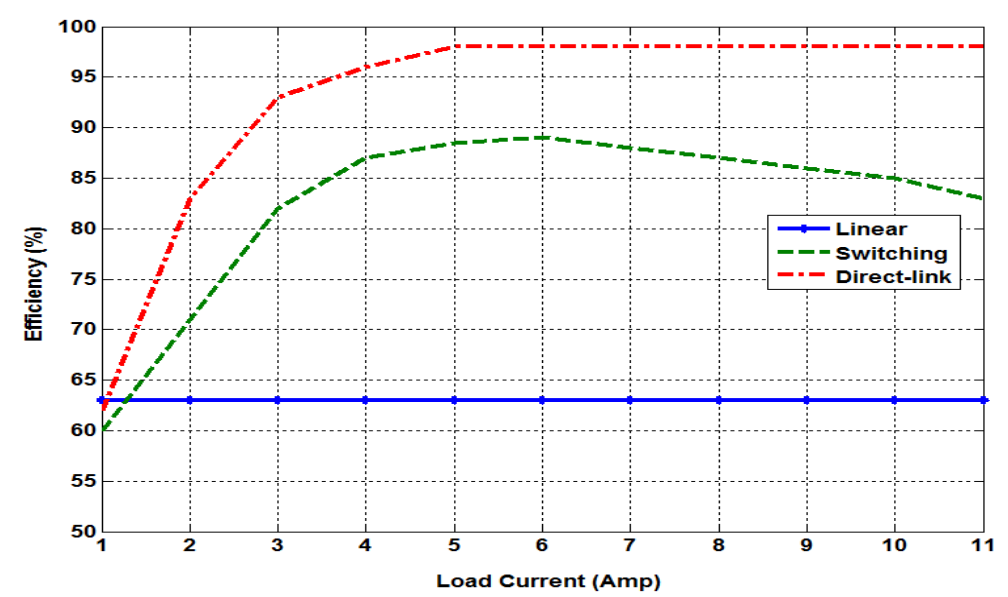

Figure 7. Efficiency curve for linear, switching and direct-link converters

To verify the performance of the proposed topology undersupplying power from solar PV, we compare the proposed system with the traditional one. Figure 8 shows the waveforms of the simulation results that have been conducted by MATLAB-Simulink. Figure 8(A) represents irradiance waveform that applied to both topologies, The output power of the proposed model is shown in Figure 8(B), it zoomed in one area to show the shape of the narrow variation of this waveform as seen in Figure $8(\mathrm{C})$. The state of charge (SOC) is displayed in Figure 8(D), where the point at which the SOC reaches the full charge $(100 \%)$ is highlighted. The SOC is the significant quantity that this comparison evaluates the proposed topology, where, under this applied conditions, the traditional topology achieves the full charge (100\% SOC) in more than 8000 seconds, while it is less than 8000 second for the proposed circuit, as shown in Figure 8(E). Following the input sun irradiance and the feedback change in the surface temperature of the solar panel under test, the output power to charge the battery is shown in Figure 8(F), while the part of the power that will use for solar ventilation or other purposes is shown in Figure $8(\mathrm{G})$. 

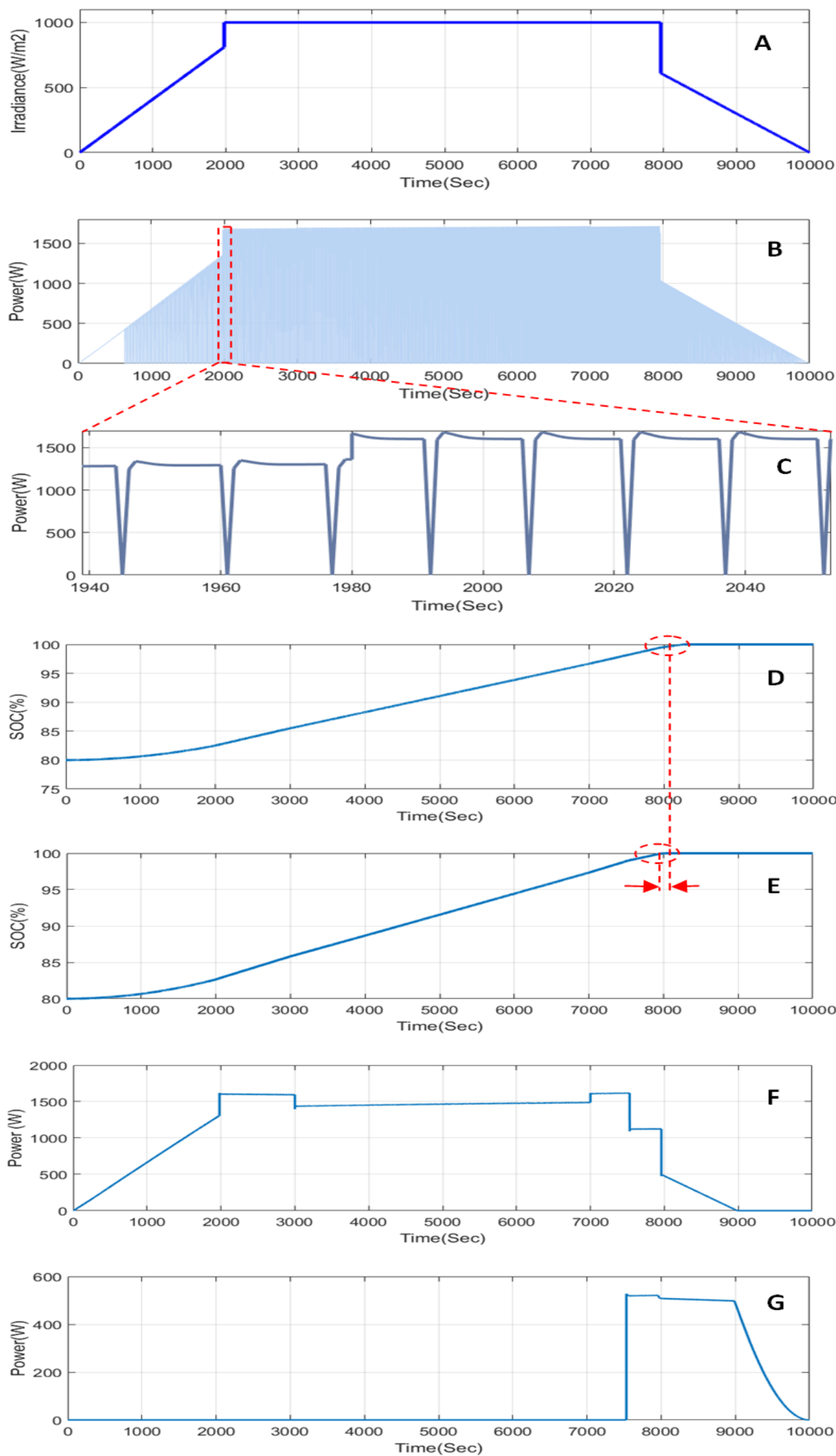

Figure 8. Comparison outcomes between the proposed and the traditional topology, (A) the simulation input irradiance, (B) the output power of traditional topology, (C) zoom-in of the output power of traditional topology, (D) SOC\% of traditional topology, (E) SOC\% of the proposed system, (F) output power of the proposed system, $(\mathrm{G})$ the cooling part from the delivered power 


\section{CONCLUSION}

The effort in this article developed an optimal strategy to control the flow of energy for a backup power system energized by solar PV or normal utility outlets depends on supply availability. Furthermore, a source-load matching concept is employed to manage the energy conversion based on the energy source availability of the system. A discussion of BPSs has been presented in order to clarify the variety of backup power topologies, and the basic concept of their control strategies. The classification of the BPSs has been discussed according to their main converter design, some advantages and disadvantages, and efficiency. The result presents the comparative analysis in terms of efficiency for the three different systems to offer helpful information in the selection of the control scheme for BPS applications. The proposed direct-link $\mathrm{DC} / \mathrm{DC}$ or AC/DC converter model proves great performance in terms of lower power losses during the conversion process. The proposed system control scheme can also be implemented for solar charge controller in PV systems and in the hybrid energy power systems. This topology with DC-distribution enhancement expands its application to be used in the smart grid and bring new trends for research and developments in this area. Experimental power measurements have been conducted to evaluate the source-load matching concept and the circuit efficiency with respect to a voltage level to verify its operational effectiveness. The result enhances the proposed concept which considers the balancing between the source and the battery voltages. The proposed topology can achieve about $99 \%$ power efficiency as compared with the traditional one. Future work is planned to conduct extensive experimental results to verify the simulation outcomes of this paper.

\section{ACKNOWLEDGEMENTS}

The author would like to thank Universiti Putra Malaysia and University Tenaga National for supporting this research work under supervision and Ministry of Education for funding this study under the MOE-FRGS scheme (03-01-17-1893FR).

\section{REFERENCES}

[1] J. M. Guerrero, L. G. de Vicuña, and J. Uceda, “Uninterruptible Power Supply Systems Provide Protection, ” IEEE Ind. Electron. Mag., 2007.

[2] A. Windhorn, “A Hybrid Static/Rotary UPS System,” vol. 28, no. 3, 1992.

[3] M. S. Racine, J. D. Parham, and M. H. Rashid, "An Overview of Uninterruptible Power Supplies," in Proceedings of the 37th Annual North American Power Symposium, 2005.

[4] T. Ma, H. Yang, and L. Lu, "Solar Photovoltaic System Modeling and Performance Prediction," Renewable and Sustainable Energy Reviews, vol. 36. pp. 304-315, 2014

[5] A. De Bernardinis, M. C. Péra, J. Garnier, D. Hissel, G. Coquery, and J. M. Kauffmann, "Fuel Cells Multi-Stack Power Architectures and Experimental Validation of 1kW Parallel Twin Stack PEFC Generator Based on High Frequency Magnetic Coupling Dedicated to on Board Power Unit," Energy Convers. Manag., 2008.

[6] Heng Deng, R. Oruganti, and D. Srinivasan, "Modeling and Control of Single-Phase UPS Inverters: A Survey," in 2005 International Conference on Power Electronics and Drives Systems, 2005.

[7] M. Niroomand and H. R. Karshenas, "Review and Comparison of Control Methods for Uninterruptible Power Supplies," in PEDSTC 2010 - 1st Power Electronics and Drive Systems and Technologies Conference, 2010.

[8] M. Aamir, K. Ahmed Kalwar, and S. Mekhilef, "Review: Uninterruptible Power Supply (UPS) System," Renewable and Sustainable Energy Reviews, 2016.

[9] A. H. Sabry, W. Zuha, W. Hasan, F. H. Nordin, Y. Alkubaisi, and M. Z. A. Ab-kadir, "Battery Backup Power System for Electrical Appliances with Two Options of Primary Power Sources," in 2018 IEEE 5th International Conference on Smart Instrumentation, Measurement and Applications (ICSIMA 2018) 28-30 November 2018, Songkhla, Thailand, pp. 28-30, 2018.

[10] M. Seyedmahmoudian, R. Rahmani, S. Mekhilef, A. Maung Than Oo, A. Stojcevski, T. K. Soon, and A. S. Ghandhari, "Simulation and Hardware Implementation of New Maximum Power Point Tracking Technique for Partially Shaded PV System Using Hybrid DEPSO Method," IEEE Trans. Sustain. Energy, vol. 6, no. 3, pp. 850-862, 2015.

[11] M. Berrera, A. Dolara, R. Faranda, and S. Leva, "Experimental Test of Seven Widely-Adopted MPPT Algorithms," in 2009 IEEE Bucharest PowerTech: Innovative Ideas Toward the Electrical Grid of the Future, 2009.

[12] H. Rezk and A. M. Eltamaly, "A Comprehensive Comparison of Different MPPT Techniques for Photovoltaic Systems,” Sol. Energy, vol. 112, pp. 1-11, 2015.

[13] T. Alnejaili, S. Drid, D. Mehdi, L. Chrifi-Alaoui, R. Belarbi, and A. Hamdouni, "Dynamic Control and Advanced Load Management of a Stand-Alone Hybrid Renewable Power System for Remote Housing," Energy Convers. Manag., 2015.

[14] A. H. Sabry, W. Z. Wan Hasan, M. Zainal, M. Amran, and S. B. Shafie, "DC Loads Matching Technique as an Alternative to AC Inverter in Residential Solar System Application Evaluation and Comparison," Appl. Mech. Mater., vol. 785, pp. 225-230, 2015. 
[15] A. H. Sabry, W. Z. W. Hasan, M. A. Kadir, M. A. M. Radzi, and S. Shafie, "Processing and Monitoring Algorithm for Solar-Powered Smart Home in DC-Environment System Based on RF-Radio Node, vol. 10607 LNAI. 2017.

[16] A. H. Sabry, W. Z. W. Hasan, M. Z. A. Ab Kadir, M. A. M. Radzi, and S. Shafie, "DC-Based Smart PV-Powered Home Energy Management System Based on Voltage Matching and RF Module," PLoS One, vol. 12, no. 9, pp. 1-22, 2017.

[17] Y. H. Sabry, W. Z. W. Hasan, A. H. Sabry, M. Z. A. A. Kadir, M. A. M. Radzi, and S. Shafie, "MeasurementBased Modeling of a Semitransparent CdTe Thin-Film PV Module Based on a Custom Neural Network," IEEE Access, vol. 6, pp. 34934-34947, 2018.

[18] A. T. Elsayed, A. A. Mohamed, and O. A. Mohammed, "DC Microgrids and Distribution Systems: An Overview," Electr. Power Syst. Res., vol. 119, pp. 407-417, 2015.

[19] V. Prabhala, B. Baddipadiga, P. Fajri, and M. Ferdowsi, "An Overview of Direct Current Distribution System Architectures \&amp; Benefits," Energies, vol. 11, no. 9, p. 2463, 2018.

[20] Y. Liu, A. Pratt, P. Kumar, M. Xu, and F. C. Lee, "390V Input VRM for High Efficiency Server Power Architecture," in Conference Proceedings - IEEE Applied Power Electronics Conference and Exposition - APEC, 2007.

[21] H. Dehbonei, S. R. Lee, and H. Nehrir, "Direct Energy Transfer for High Efficiency Photovoltaic Energy Systems Part I: Concepts and hypothesis,” IEEE Trans. Aerosp. Electron. Syst., 2009.

[22] J. P. Lee, B. D. Min, J. J. Kim, K. Y. Ryul, T. J. Kim, D. W. Yoo, E. H. Song, and J. N. Yoo, “A New Topology for Photovoltaic 4 Series DC/DC Converter with High Efficiency under Wide Load Range," in 7th Internatonal Conference on Power Electronics, ICPE'07, 2008.

[23] W. Zhang, D. Xu, X. Li, R. Xie, H. Li, D. Dong, C. Sun, and M. Chen, "Seamless Transfer Control Strategy for Fuel Cell Uninterruptible Power Supply System,” IEEE Trans. Power Electron., 2013.

[24] Y. Zhan, Y. Guo, J. Zhu, and L. Li, "Performance Comparison of Input Current Ripple Reduction Methods in UPS Applications with Hybrid PEM Fuel Cell/Supercapacitor Power Sources,” Int. J. Electr. Power Energy Syst., 2015.

[25] Y. Zhan, Y. Guo, J. Zhu, and L. Li, "Power and Energy Management of Grid/PEMFC/Battery/Supercapacitor Hybrid Power Sources for UPS Applications," Int. J. Electr. Power Energy Syst., 2015.

[26] T. S. Gunawan, I. R. H. Yaldi, M. Kartiwi, and H. Mansor, "Performance Evaluation of Smart Home System using Internet of Things," International Journal of Electrical and Computer Engineering, vol. 8, pp. 400-411, 2018.

[27] T. S. Gunawan, I. Rahmithul, H. Yaldi, M. Kartiwi, and N. Ismail, "Prototype Design of Smart Home System using Internet of Things," Indonesian Journal of Electrical Engineering and Computer Science, vol. 7, pp. 107-115, 2017.

\section{BIOGRAPHIES OF AUTHORS}

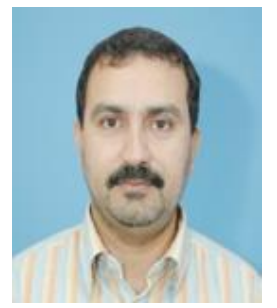

Ahmad H. SABRY was born in Baghdad, Iraq. He received the B.Sc. and M.Sc. degrees in electrical and electronics, control and automation, engineering from the University of Technology-Baghdad, Iraq, in 1994 and 2001, respectively. He received the Ph.D. degree in DCBased PV-Powered Home Energy System from Department of Electrical and Electronic Engineering, control and automation at UPM, Malaysia in 2017. He is the author of more than 35 articles, and more than 5 inventions, and holds one patent. His research interests include Integrated Solar Powered Smart Home System Based On Voltage Matching, DC distribution, industrial robotic systems, wireless energy management systems. He is currently a post-doctorate researcher in Universiti Tenaga Nasional (UNITEN).

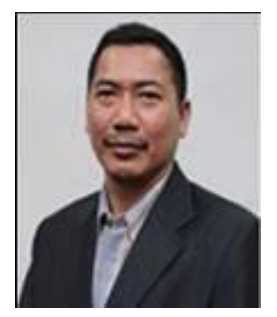

W. Z. W. Hasan received the degree in Electrical and Electronic Engineering from Universiti Putra Malaysia in 1997. He received the Ph.D. degree in Microelectronic Engineering from the Universiti Kebangsaan Malaysia in 2010. Currently, he is a senior lecturer at Department of Electrical and Electronic Engineering, Universiti Putra Malaysia. His research interests include Memory Testing, MEMS Sensor and Robotic and Automation.

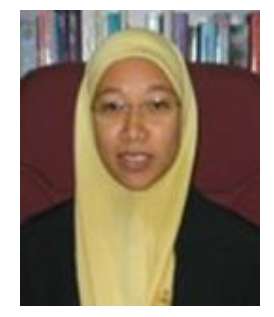

Farah Hani Bte Nordin, received the PhD in Engineering, Universiti Tenaga Nasional, 2010, MSc. in Control, Communication and DSP, University of Strachlyde, 2002, BSc. (Hon.) in Electrical \& Electronic Engineering, UNITEN, 2000. She is a Head of Department Electronics \& Communication Eng., $\quad$ UNITEN, 2014 - 2018. Senior Lecturer, UNITEN, 2009-2018. Head of Unit Academic (BEEE), UNITEN, 2011-2014. Lecturer, UNITEN, 2002-2009. Tutor, UNITEN, 2000-2002 


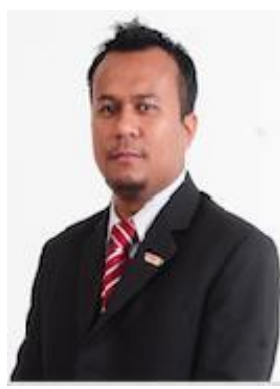

Moh Zainal Abidin Ab Kadir received his B.Eng. degree in Electrical and Electronic Engineering from Universiti Putra Malaysia and the Ph.D. degree in high-voltage engineering from the University of Manchester, U.K. Currently, he is the Deputy Dean (Research \& Innovation) and Professor at the Faculty of Engineering, Universiti Putra Malaysia, Selangor, Malaysia. He is also the Director at the Centre for Electromagnetic and Lightning Protection Research (CELP), Universiti Putra Malaysia. Professor Zainal is a Professional Engineer (PEng) and a Chartered Engineer (CEng) and currently is the Chairman of National Mirror Committee of TC 81 (Lightning Protection), Chairman of MNC-CIGRE C4 on System Technical Performance, Working Group Member of IEEE PES Lightning Performance on Overhead Lines, CIGRE C4.23 and CIGRE C4.27. He is a member of IET, IEM, CIGRE and a Senior Member of IEEE. To date he has authored and co-authored over 300 technical papers comprising of high impact journals and conference proceedings. He has supervised $9 \mathrm{PhD}$ and $24 \mathrm{MSc}$ students and currently $17 \mathrm{PhD}$ and $15 \mathrm{MSc}$ are on their way. His research interests include high voltage engineering, electromagnetic compatibility and power system transients. 